\title{
Geotechnical data collection and approach to modelling for the Cukaru Peki deposit
}

\author{
K Llewelyn SRK Consulting (UK) Ltd, UK \\ J Jakubec SRK Consulting (Canada) Inc. Canada, Canada \\ R Goddard SRK Consulting (UK) Ltd, UK \\ P Stenhouse Polyphase Consulting Ltd, New Zealand
}

\begin{abstract}
A geotechnical model is the fundamental basis for the design of an open pit and underground mine. A fully understood and representative geotechnical model will provide information on the engineering characteristics of the rock mass, defining how it is going to behave during mining. The model is composed of individual domains, each comprised of materials exhibiting internally similar geotechnical properties. Defining these domains and fully understanding what is critical to the excavation and the associated risks will enable the mine planners to design the optimal mine.

A geotechnical model that will add value to a mine design should be developed based on a thorough understanding of the 3D geology, structure and, where relevant, alteration and weathering states of the deposit and how these impact the engineering properties. The geotechnical specialist should have a good understanding of the risks and limitations of each individual model and how these will impact on developing the geotechnical domains.

A representative geotechnical model is only as good as the data that is available for the deposit. This paper presents the different types of data used to develop the geotechnical model for the Cukaru Peki deposit and the approach adopted for creating a representative geotechnical model that was used for mine planning.
\end{abstract}

Keywords: geotechnical data collection, geotechnical model, Cukaru Peki

\section{Introduction}

A geotechnical model is the fundamental basis for the design of an open pit and underground mine. A fully understood and representative geotechnical model will provide information on the engineering characteristics of the rock mass, defining how it is going to behave during mining. The model is composed of individual domains, each comprised of materials exhibiting internally similar geotechnical properties. Defining these domains and fully understanding what is critical to the excavation and the associated risks will enable the mine planners to design the optimal mine.

Developments in software have improved modelling workflow, allowing models to be built in a true, open 3D environment using implicit or semi-implicit modelling routines. The modelling routines are guided by the data selection, the application of trends, and definition of geological rules, and the resulting surfaces can typically be readily manually edited by the modeller. These advances in software have enabled modellers to create more complex models, which can be rebuilt instantly, to include new data or geological rules and reflect multiple interpretations from many large data sources. Whilst these developments in software bring benefits to understanding the complexity of a deposit, it is imperative that the data that is being used is adequate and the quantity, quality and appropriateness has been evaluated by the modeller prior to using the data and embarking on a modelling exercise.

A geotechnical model that will add value to a mine design should be developed based on a thorough understanding of the geology, structure and, where relevant, alteration and weathering states of the deposit 
and how these impact the engineering properties. The geotechnical specialist should have a good understanding of the risks and limitations of each individual model and how these will impact on developing the geotechnical domains.

This paper presents the different types of data used to develop the geotechnical model for the Cukaru Peki deposit and the approach adopted for creating a representative geotechnical model that was used for mine planning.

\section{Project description}

The Cukaru Peki Upper Zone and Lower Zone are part of the Timok copper-gold project. Nevsun Resources Ltd owns $100 \%$ of the Cukaru Peki Upper Zone and the Lower Zone is a joint venture with Freeport-McMoRan Exploration Corporation. The Timok project is located within the central zone of the Timok Magmatic Complex (TMC) in the Serbian section of the East European Carpathian-Balkan Arc. The TMC has one of the highest concentrations of copper enrichment in the Tethyan Belt. A location plan is provided in Figure 1.

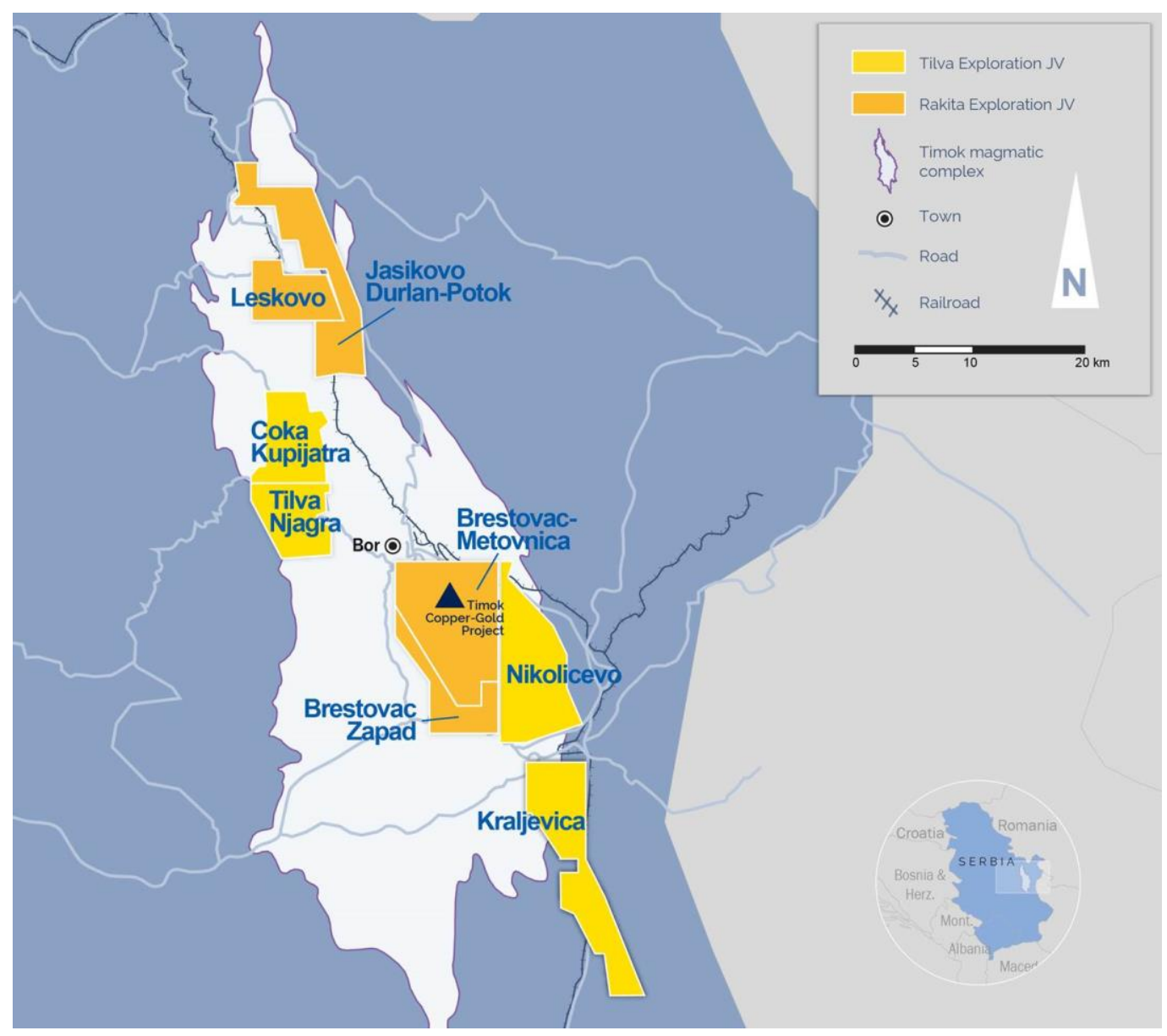

Figure 1 Location plan (Nevsun Resources Ltd 2017) 
The upper zone of the Cukaru Peki mineralisation occurs at depths between 400 to $800 \mathrm{~m}$ below ground level (BGL). The deposit does not outcrop on the surface as it is buried beneath Miocene clastic sedimentary (MCS) rocks which unconformably overlie the Upper Cretaceous Bor Conglomerate (UCCM), Upper Cretaceous Bor Marl (UCMA) and smaller units of volcaniclastic and volcanic rocks. The Unaltered Andesite (UA) sits below the unconformity and the Lower Andesite (LA) below that, consisting of hornblende and hornblende-biotite andesite, andesite breccia, hydrothermal breccia, and relatively rare diorite porphyry.

The high sulphidation epithermal (HSE) mineralisation found within the LA comprises massive sulphide (MS), semi-massive sulphide (SMS), and vein, stockwork, dissemination and hydrothermal breccia matrix sulphide. Pyrite is the dominant sulphide mineral, and the principal copper mineral is covellite with lesser enargite, bornite and chalcocite occurring in veins, hydrothermal breccias, disseminations and replacement. Gold is associated primarily with the copper sulphides.

The top of the mineralisation is constrained by the unconformity and the lateral extents are constrained by faulting, which are also present in the mineralisation. Several alteration assemblages are present in the LA, which have been grouped into four main types of alteration, being an advanced argillic (AArg) alteration core surrounded by an argillic kaolinite (ArgK) halo, argillic (Arg) alteration and then mostly phyllic and propylitic alteration (PP) at its base. The HSE is found within the AArg with higher grades of copper and gold near the cap and then gradationally decreasing with depth.

A cross-section of the geology and alteration model is provided in Figure 2.

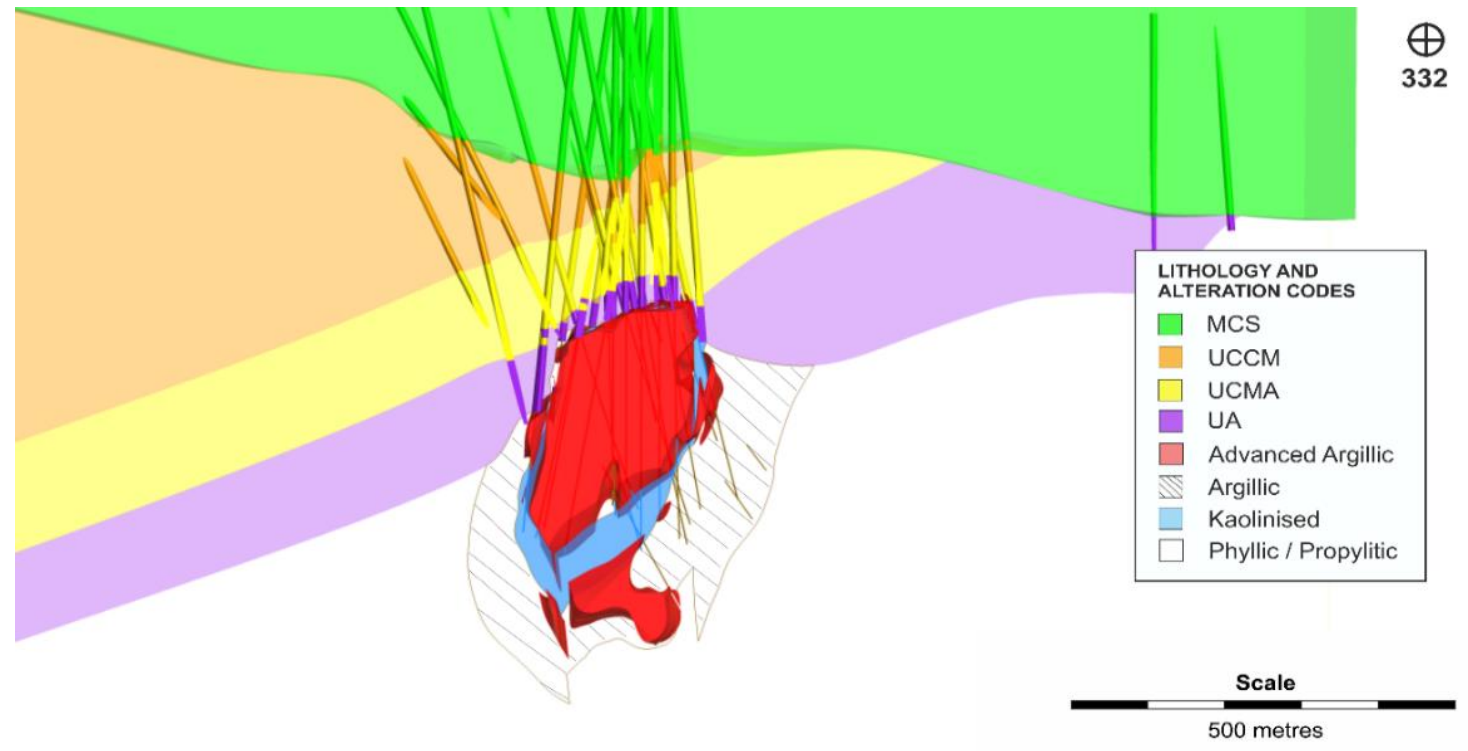

Figure 2 Cross-section of geology and alteration model (facing towards $332^{\circ}$ )

\section{Approach to geotechnical data collection and modelling}

Early involvement in exploration drilling programs from geotechnical specialists is key to setting up the geotechnical data collection. Often, the focus of a drilling program is to define the resource, and little thought is given to the data that is required to understand how the resource is going to be mined. The flow chart presented in Figure 3 sets out the approach to geotechnical data collection and modelling used for the Cukaru Peki Preliminary Economic Assessment (PEA) study. 
CUMULATIVE DRILLING TOTALS

(R) Resource

(GT) Geotechnical

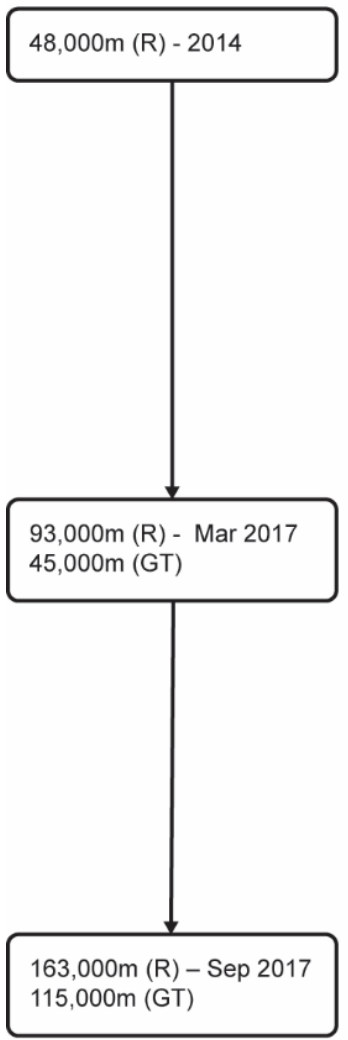

DRILLING PHASES

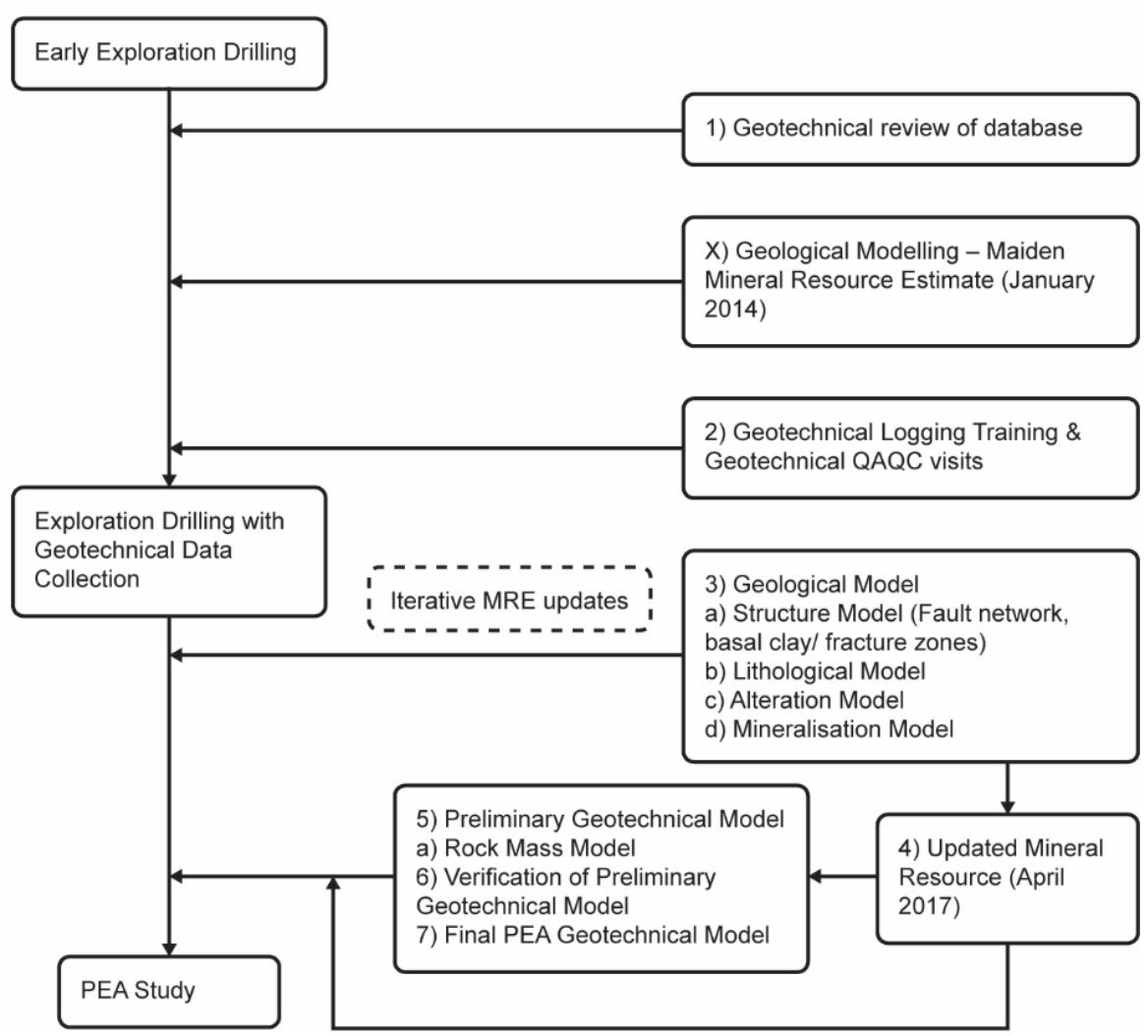

Figure 3 Approach to data collection and modelling

The steps within this flow chart have been described in further detail to demonstrate how the geotechnical data collection program was set up for the Cukaru PEA and subsequently, how the data was used to develop the geotechnical domain model.

\section{$4 \quad$ Geotechnical review of database}

A review of the lithology, alteration, structure and hydrogeology in the context of the geotechnical characterisation for the deposit was carried out after exploration drilling commenced. The objective of the review was to get an understanding of the geometry of the orebody and the rock mass conditions, and to identify early in the study the critical factors to be considered for mining the orebody. It was evident that the geology, and ultimately the type and intensity of alteration, were key to understanding the strength and quality of the rock mass and subsequently how it would behave during excavation. Weakening argillic alteration, associated with late, low-temperature hydrothermal activity was recorded at some distance from observed major structures. A brittle structural fabric was noted throughout the deposit area, manifested through persistent faults (offsetting the orebody) and well-developed joint systems, which would influence the underground mining. Recommendations were provided on the basis for developing the next steps in the data collection. The geotechnical review is a key step that needs to take place early in the drilling program to maximise the amount of data being collected from the drillhole. 


\section{$5 \quad$ Geotechnical logging training and QA/QC visits}

Geotechnical logging training was provided to an experienced geology team, assigning key members of the team to manage the geotechnical data collection. The intent of the logging training was to provide the site personnel with the information, tools and manuals to enable them to capture the required geotechnical data for carrying out a cave mining study. A holistic approach to the logging was used to capture geological and alteration data, large- and small-scale structure, and geotechnical rock mass data.

The rock mass logging focused on collecting data to calculate Laubscher's RMR ${ }_{90}$ (Laubscher 1990) and Barton's Q (Barton 1988) for classifying the rock mass. The core was orientated and small-scale structure logging was carried out. Major structure logging focused on classifying potential faulted rock intervals recording quality, cohesive strength and observation class, which were used to describe the potential intervals of faulted rock for major structure interpretation. Geotechnical domain logging was used to combine intervals of core with similar geotechnical properties and identify any intervals with varying rock mass quality.

A series of workshops and check logging visits were carried out over the duration of the drilling program focusing on ensuring that the geologists were logging the core to a satisfactory level of detail. It was critical that these QA/QC visits were spent in the core store with the various geologists involved so that everyone knew the requirements of the logging, methodology and how the data should be collected. Independent check core logging was carried out and used as a basis to verify the geologists' logging, and recommendations were provided both in the core store and followed up with a site report.

The logging training, backed up with $Q A / Q C$ visits, was crucial to the geotechnical data collection program and ensured that a reliable database, stored and managed using acQuire software (acQuire Technology Solutions Pty Ltd 2018), was developed for the project. The size of the geotechnical database used for creating the PEA geotechnical model is provided in Table 1.

Table 1 Data used for the PEA geotechnical model

\begin{tabular}{|c|c|}
\hline Data & Description \\
\hline Collar and survey data & Collar and survey data for the 211 drillholes \\
\hline Geology logs & Geological logs for 211 drillholes and 163,000 m \\
\hline Geotechnical logs & $\begin{array}{l}\text { Detailed geotechnical logs for } 166 \text { drillholes and } \\
119,000 \mathrm{~m}\end{array}$ \\
\hline Geomechanical testing & A suite of geomechanical testing was carried out \\
\hline Downhole acoustic borehole imagery ( $\mathrm{ABI}$ ) data & $\begin{array}{l}\text { Structure picking from } 56 \mathrm{ABI} \text { drillholes and 70,000 } \\
\text { discontinuities }\end{array}$ \\
\hline
\end{tabular}

\section{Preliminary geotechnical model}

The preliminary geotechnical model was developed on the basis of geological domains, which were developed primarily from drillhole data for structural observations, alteration and lithological logging. These domains were also used to develop the framework for the project's mineral resource.

The objective of preparing a preliminary geotechnical model early on in the drilling program was so that it could then be used as a basis for the team's understanding of the different geotechnical domains. It enabled the team to understand what is critical to the modelling and what data should take precedence when developing the model. The preliminary model became a working platform to update as more drilling results became available. Several iterations of this preliminary model were developed to ensure that a representative model was created for the PEA. 
The steps taken to develop the model and the order that they were created are described in the following sections.

\subsection{Structural model}

A major structure model was created to define the location, orientation and nature of the faults and fractured zones present in the deposit and was used for defining the geometry of the orebody, domaining the rock mass and locating the mine infrastructure.

Prior to the modelling, a major structure core photo logging campaign was carried out to classify the faulted rock intervals. The logging focused on describing the physical attributes, deformation intensity, confidence in the structure and the significance it had to the modelling. The confidence was measured from one to three and defined the likelihood that the recorded interval is actually the interpreted structure. The significance was also measured from one to three and uses the thickness of the interval and degree of fault rock development and/or fracture intensity as a proxy for the relative importance of the structural interval.

The following categories were used to classify the intervals:

- Primary Slip Zone (PSZ): Zone of fault rock development. May also include damage zone where the damage zone is thin relative to the width of the PSZ. High confidence.

- Possible PSZ: As above, but with a lower level of confidence.

- Multi-PSZ (MSZ): Zone with a number of small, relatively close-spaced PSZs within a broader zone of fracturing.

- Damage Zone (DZ): Zone of increased fracturing and minor faulting adjacent to a major PSZ.

- Clay or Clay Fracture Zone (CLAY/CFZ): Typically, large intervals of increased clay alteration, associated with fracturing and some minor faulting.

- Fracture Zone (FZ): Fracturing not associated with a potential PSZ or a significant increase in clay content.

The following data was also used to assist in understanding the geometry of the structural framework and how the individual faults were connected:

- $A B I$ information (with associated confidence and significance ranking values) relating to the orientation of interpreted boundaries of potential PSZs.

- Major structure logs containing information on the type, intensity and confidence of the faulted rock from the drillholes.

- Visual offsets in the geological logging data and downhole copper assay grades.

- Geotechnical logging data, specifically the Rock Mass Rating (RMR), Rock Quality Designation (RQD), fracture frequency (FF) and intact rock strength (IRS).

Intervals of similar physical and structural classification were grouped together within the context of local orientation data to define structural fault domains with reasonable 3D geological continuity. The structural domains were adjusted, where applicable, to better reflect the geotechnical logging data by locally expanding or contracting the wireframe volumes to capture poor rock quality data on the periphery of the models, or conversely, to avoid favourable rock mass inside the volumes.

Each of the fault domains were assigned a confidence category to assist with geotechnical modelling. The orientation, average thickness and proportion of each logged structure type per fault were defined. For each fault, an appraisal was made as to the apparent degree of offset on the geology and mineralisation, which directly relates to the geological significance of the structures. The geotechnical significance of the structures directly relates to a combination of the orientation, thickness and fault rock type.

A 3D view of the fault model is provided in Figure 4 and a plan view in Figure 5. 


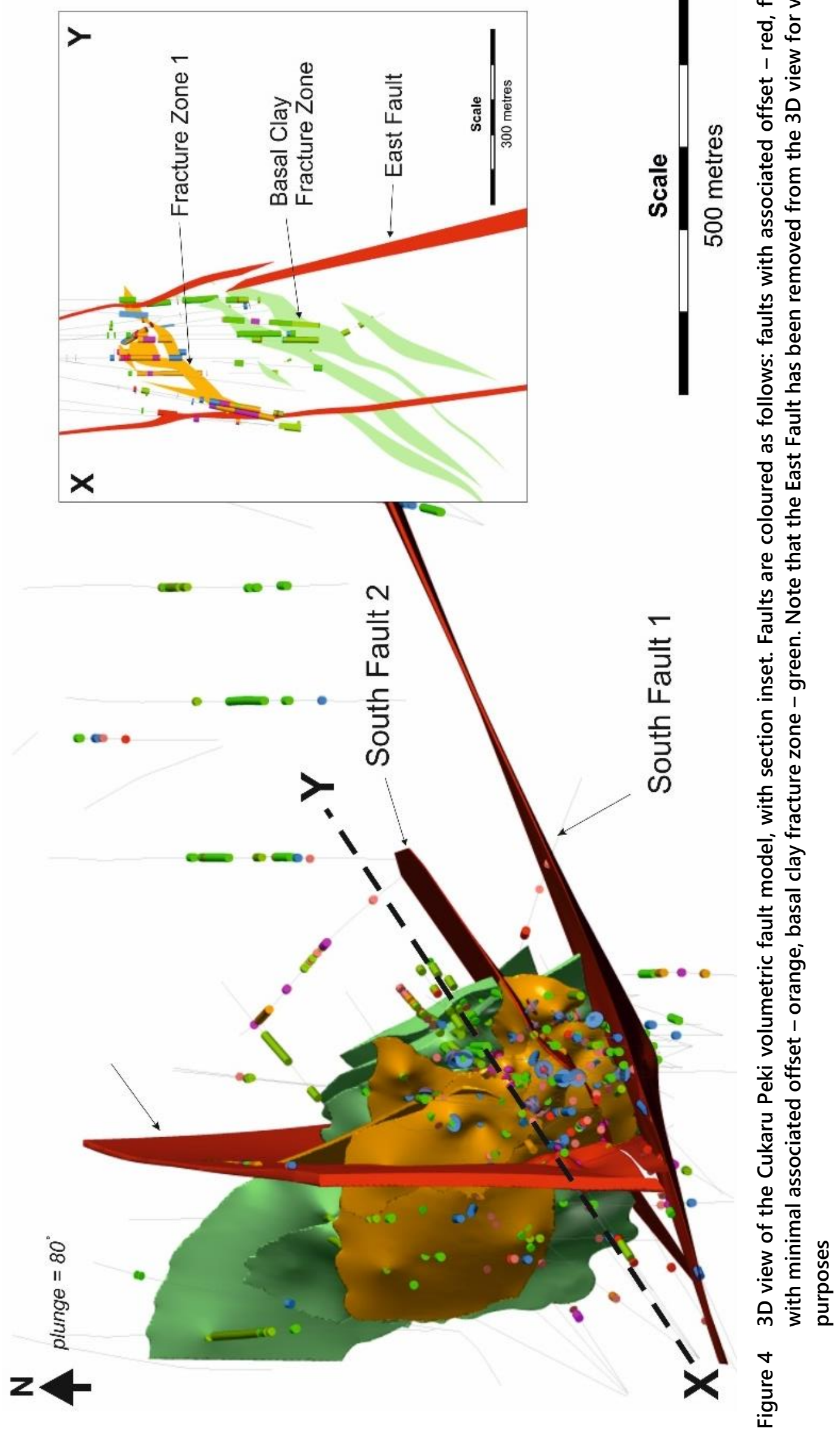




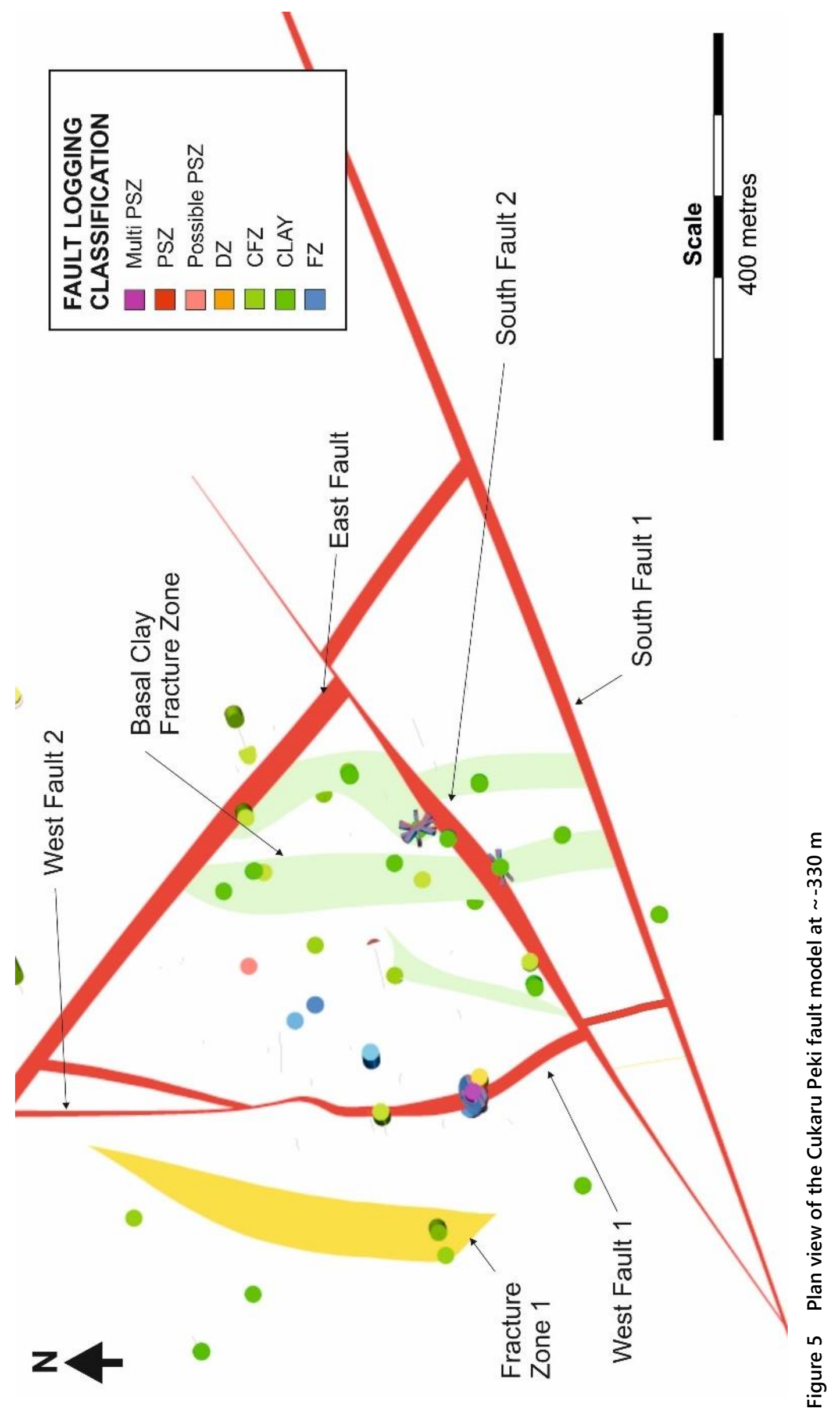




\subsection{Lithological and alteration modelling}

The unmineralised stratigraphic cover sequence was modelled as a series of surfaces above the LA which hosts the mineralisation (and associated alteration), based on geological logging data. The LA was interpreted to have zones of higher and lower porosity, with the more coherent, less porous rock at the margins of the deposit considered to coincide with the contact between mineralisation and waste. The LA was modelled using a combination of surfaces and implicit shells, based on geological logging codes, to reflect a relatively uniform contact with the overlying UA sill and more geometrically variable contact at depth between mineralised and unmineralised parts of the LA.

Alteration modelling was carried out using Leapfrog Geo v4.1.1 software (ARANZ Geo Ltd 2016) using Terraspec spectrometer readings and logged alteration assemblages as the main explicit control on the model. The Terraspec log provides presence/absence data and relative abundance for up to nine alteration minerals per interval. The alteration style and intensity was collected and interpreted by the client's geologists, in the context of visual assessment of the drill core, in order to provide an alteration assemblage code for each interval. A total of 11 unique assemblage codes are present in the alteration log. These codes have been grouped into the advanced argillic, argillic, kaolinite and phyllic/propylitic main assemblages to ensure reasonable continuity in the model. The advanced argillic, argillic and phyllic/propylitic domains were derived directly from grouping of the alteration assemblage codes, whilst the kaolinite code represents sample intervals for which kaolinite (kao) is present but alunite (alun), pyrophyllite (pph) and dickite (dck) minerals are absent.

The advanced argillic, argillic and phyllic/propylitic domains were modelled as broadly concentric shells. The kaolinite domain forms a halo of variable thickness $(10$ to $70 \mathrm{~m})$ around the outside of the advanced argillic domain, typically marking the transition between advanced argillic and argillic alteration. The faults were used to generate a series of fault-bounded domains, and the alteration domains were subsequently constructed independently within each of the separate fault blocks. The structures considered to offset the alteration domains include South Fault 1, South Fault 2, West Fault 1 and East Fault.

The alteration model has been constrained below the UA-LA contact. The stratigraphic sequence above this contact, incorporating from top to bottom, the MCS, UCCM, UCMA and UA were modelled using the stratigraphic modelling tools in Leapfrog Geo. Similar to the alteration model, the stratigraphic model was constructed independently within a series of fault bounded domains based on the structures considered to account for appreciable offset on the stratigraphic succession. These are South Fault 1, West Fault 1, East Fault and South Fault 3.

\subsection{Rock mass model}

The rock mass logging data were imported into Leapfrog Geo to assess the spatial variability in the geotechnical parameters. The approach from the outset of the rock mass modelling was to create wireframes based on the RQD, FF/M, IRS and RMR using the alteration and structure model to provide the trends and constraints for the domains. The visual assessment and modelling of the data indicated that the spatial variability in the geotechnical parameters correlated well with the geology, alteration and structure. The geotechnical data was assigned codes reflecting the alteration and structure domains, and a statistical analysis was carried out on the geotechnical parameters to assess the representativeness of the geotechnical conditions in each domain.

A logical approach was used to develop the preliminary geotechnical model that takes into consideration the geological, alteration and structural conditions for the deposit. There is generally a good correlation between the geological framework and geotechnical parameters, i.e. the geotechnically weaker, less competent rock correlates with the geologically domained fault/fracture zones and less competent Arg and ArgK alteration domains. 
The use of alteration and structural logging to inform the geotechnical assessment has resulted in an initial geotechnical model with a reasonable geological basis. The use of $A B I$ data in constructing this model, in addition to the categorisation of logged faults according to their physical characteristics, has enabled the correlation of similar zones, constrained by a structural and geological framework, in a way that would not be possible using geotechnical data alone.

\section{$7 \quad$ Verification of preliminary geotechnical model}

The preliminary geotechnical model was provided to the geologists so that it could be verified and checked as more drilling results became available. The approach to the verification was for the geologists to prepare a series of geological and geotechnical cross-sections through the deposit. The geological cross-sections focused on understanding the geometry of the mineralisation, lithology and alteration. Included in the geology cross-sections were interpretations of the major structures based on the complexity of the mineralisation and lithology. The geotechnical cross-sections focused on understanding the variability in the rock mass class, with independent interpretations of the major structures present. This was an interactive, evolving process with the aim to involve the geologists so that they could check the model that was provided against their interpretations of the deposit. Also, they could plot up any new drilling data that became available to test that the preliminary geotechnical model was representative of the deposit. Some of the examples of the geotechnical cross-sections developed by the geologists are provided in Figure 6 .
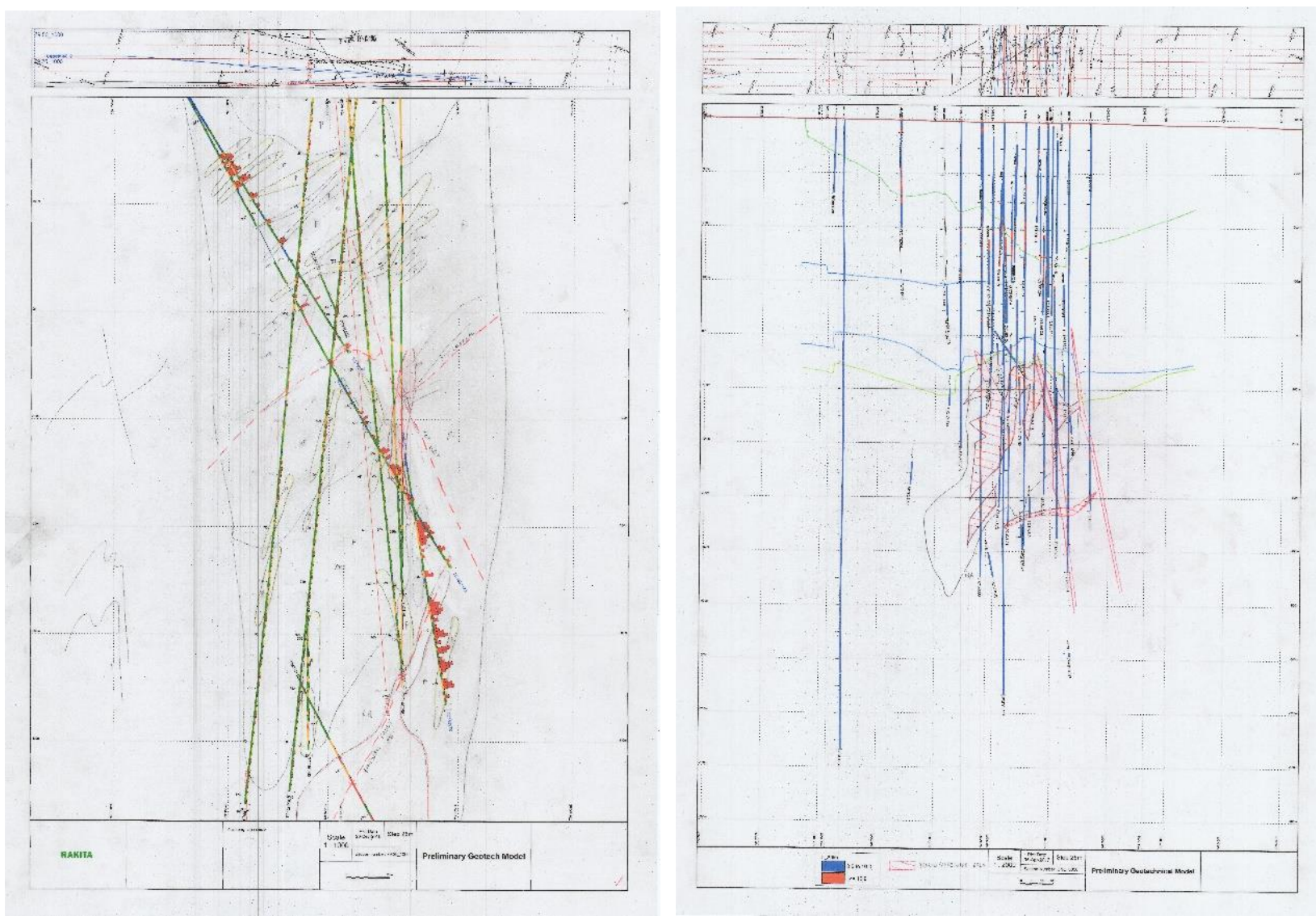

Figure 6 Geotechnical cross-sections developed by site geologist 


\section{Final PEA geotechnical model}

The final geotechnical model that was used for the PEA study had undergone several iterations taking into consideration the new drilling data that had become available along with the updated interpretations of the individual models used to create the geotechnical model. The model was used as a basis for characterising the rock mass and subsequently carrying out assessment to provide inputs to the cave mining study.

The rock mass assessment was conducted as follows:

- The geological, alteration and structure wireframes were used to assign codes to each geotechnical data record such as the geotechnical drillhole logging intervals, core orientation structure logging and the $A B I$ structure picking.

- Assigning the codes has been prioritised into three groups to ensure that the poorer rock mass quality in the faults and fractured domains can be identified from the database, as follows:

- Structure domains (Basal Clay Fracture Zone 1 and 2, East Fault 1, Fault 3a Fracture Zone 1 and 2, South Fault 1 and 2, and West Fault 1 and 2).

- Alteration domains (advanced argillic, kaolinite halo, argillic, phyllic and propolytic).

- Geological domains (MCS, UCCM, UCMA, UA, LA).

- The hanging wall, orebody and footwall domains are represented by the UA, advanced argillic and argillic domains respectively.

- Datasets have been assessed independently in order to evaluate:

- How basic rock mass parameters compare between datasets (i.e. RQD, IRS), FF, joint set number (Jn), joint roughness (Jr), joint alteration (Ja).

- How Laubscher's RMR 90 and Barton's Q values compare between datasets.

The rock mass assessment was carried out using Leapfrog v4.1.1, which enables the user to define geotechnical domains and assess the spatial variability in the rock mass using the information contained in the drilling database. The information contained in the drilling database was assigned to the geotechnical domains listed above for assessing the difference in the rock mass parameters.

A statistical analysis of the geotechnical parameters has been carried out for each geotechnical domain and the results are presented in Table 2 . 


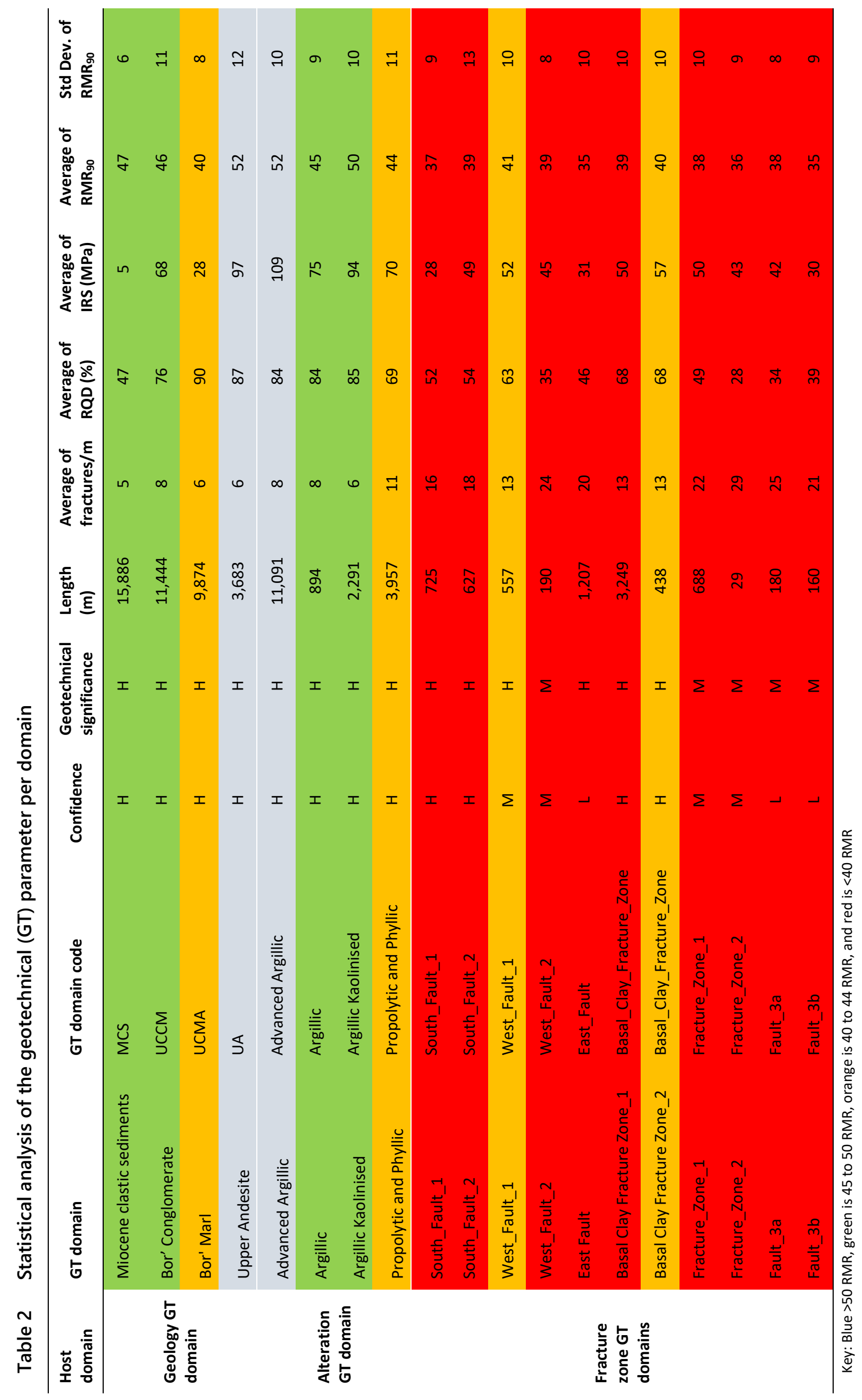


The statistical analysis of the geotechnical parameters based on the geotechnical domains indicate that the faults and fracture zone domains contain poorer quality rock than the alteration and geology domains. The faults and fracture zone domains are classified as Poor-4A, with exception of the West Fault 1 and Basal Clay Fracture Zone 2, which are classified as Fair-3B. The alteration and geological domains are classified as Fair-3B, with exception of the Upper Andesite and Advanced Argillic which are Fair-3A, and the Bor Marl being Poor-4A, based on Laubscher's RMR ${ }_{90}$ classification. The statistical analysis of the parameters for the MCS indicated that there were irregularities in the geotechnical core logging, hence why the average RQD and FF did not correlate. Further work was planned to re-log the MCS for the pre-feasibility study to provide a representative RMR.

The average FF and RQD generally confirm the domain selection with higher FF and lower RQD in the fault and fracture domains. The field-estimated IRS also confirms the domain selections with lower strengths in the fault and fracture domains than the alteration domains.

A detailed rock mass assessment was carried out for the orebody represented by the advanced argillic domain to understand the variability in rock mass quality for all the mining levels. This assessment was used to provide ground support recommendations and development advance rates for input to the mine design. A plan section was cut at each mining level to assess the expected geotechnical domains for that specific level. The core photographs for that specific level were reviewed and a statistical analysis of the RMR, RQD and FF was carried out for each mining level. The proportions of good, average and poor rock were estimated for each mining level and a design RMR value was chosen to represent the rock mass quality.

\section{Conclusion}

Only with robust and appropriate geology, structure and alteration models could a thorough assessment of the rock mass be carried out. The geotechnical data was spatially and statistically analysed relative to these models to understand how the geology and structure was affecting the rock mass engineering properties. It was evident that the structure and the alteration was controlling the variability in rock mass characteristics, and the models were used to generate the geotechnical model.

Once finalised, the data in each geotechnical domain was used for generating geotechnical parameters that could be used for inputs to the cave mining study. The real value added to the mine planning came from a succinct and in-depth knowledge of the development and use of individual models to create a geotechnical model that was representative of the actual conditions.

\section{Acknowledgement}

SRK acknowledges Nevsun Resources Ltd for allowing the publication of this technical paper and the Rakita site technical team for their hard work and effort put into this study.

\section{References}

acQuire Technology Solutions Pty Ltd 2018, GIM Suite, computer software, acQuire Technology Solutions Pty Ltd, Applecross, https://www.acquire.com.au/gim-suite/

ARANZ Geo Ltd 2016, Leapfrog Geo, version 4.1.1, computer software, ARANZ Geo Ltd., Christchurch, http://www.leapfrog3d.com/ products/leapfrog-geo

Barton, N 1988, 'Rock mass classification and tunnel reinforcement selection using the Q-System', in L Kirkdale (ed.), Rock Classification for Engineering Purposes, ASTM STP 984, American Society for Testing and Materials, Philadelphia, pp. 59-88.

Laubscher, DH 1990, 'A geomechanics classification system for the rating of rock mass in mine design', Journal of South African Institute of Mining and Metallurgy, vol. 90, no. 10, pp. 257-273.

Nevsun Resources Ltd 2017, Timok Project, Nevsun Resources Ltd, Vancouver, viewed 22 August 2018, https://www.nevsun.com/ projects/timok-project 
